\title{
Correspondence
}

\section{Dorsal continuation of the radial artery}

To the Editor:

A 50-yr-old female with no special medical problems was having root canal surgery performed by an endodontist. She informed me that I would have great difficulty finding a vein. After a prolonged search I located what I thought would be a suitable vessel on the dorsum of her hand. I was more than pleased to enter this vessel on my first attempt, using a 22GA Insyte iv catheter. After removing the tourniquet and the metal stylet, bright red arterial blood squirted out of the catheter. Arterial cannulation was confirmed by observing the blood rise rapidly towards the connected infusion bag. I immediately removed the catheter and applied a tight pressure bandage.

On follow-up two days later, the patient had a normal radial pulse on both wrists. I was able to feel a good pulse in the "vein" on the dorsum of the hand and could detect no such pulse on the other side.

Since that episode I have spoken to numerous experienced practitioners and I have yet to find anybody who has accidentally accessed an artery in this location. However, I found in Kadir's "Atlas of Normal and Variant Angiographic Anatomy" that in $1 \%$ of people there is a "dorsal continuation of the radial artery (a large branch, arising in the distal forearm, which courses to the dorsum of the hand)".

While infrequent, I felt this anatomic variation was worth mentioning. The intra-arterial injection of a number of drugs used commonly in anesthesia may have serious consequences for the patient. Awareness of such anatomical variations becomes important, specially at a time when total $i v$ anesthesia and monitored anesthesia care are so popular.

T.M. Tibbetts MD

Victoria, British Columbia

\section{Reference}

1 Kadir S. Atlas of Normal and Variant Angiographic Anatomy. Philadelphia, PA: WB Saunders, 1991.

\section{Problem with Ohmeda Excel 210 SE anesthetic machine}

To the Editor:

The Ohmeda Excel $210 \mathrm{SE}$ anesthetic machine is designed to prevent delivery of a hypoxic gas mixture when nitrous oxide is administered with oxygen. During a routine anesthetic machine check, the oxygen analyzer displayed a $\mathrm{FIO}_{2}$ of 0.15 , when nitrous oxide alone was set at $0.9 \mathrm{~L} \cdot \mathrm{min}^{-1}$. According to the anesthetic machine's operation manual, ${ }^{1}$ at $0.9 \mathrm{~L} \cdot \mathrm{min}^{-1}$ nitrous oxide flow, the oxygen flow must be between $0.24-0.36 \mathrm{~L} \cdot \mathrm{min}^{-1}$. In this anesthetic machine, the oxygen flow was noticed to be much below the recommended flow. On further inspection, minimal nominal oxygen flow on this anesthetic machine was approximately $50 \mathrm{~mL} \cdot \mathrm{min}^{-1}$, in contrast with the recommended $175-225 \mathrm{~mL} \cdot \mathrm{min}^{-1}$. Minimal nominal oxygen flow is provided by a "stop" on the oxygen flow control valve. ${ }^{2}$ The oxygen and nitrous oxide chain-link mechanism is first activated when the nitrous oxide flow reaches $600-700 \mathrm{~mL} \cdot \mathrm{min}^{-1}$. This chain-link normally ensures a minimal $\mathrm{FIO}_{2}$ of 0.25 when oxygen and nitrous oxide are used together. ${ }^{2}$ In this case, it meant that at $600-700 \mathrm{~mL}$ nitrous oxide flow oxygen flow was only $50 \mathrm{~mL} \cdot \mathrm{min}^{-1}$, which could possibly result in delivery of a hypoxic mixture to the patient. This machine was one of our new machines and had been installed only three weeks before. On inspecting the remainder of the new machines (six), all had a similar problem. The Ohmeda representative confirmed that minimal nominal oxygen flow on all machines was between 175-225 $\mathrm{mL} \cdot \mathrm{min}^{-1}$ three weeks before. Further anesthetic machine checks by the Ohmeda service engineer revealed that the oxygen nitrous oxide chain-link mechanism was operational at an $\mathrm{FIO}_{2}$ of 0.19 . Second-stage pressure regulators and the "stop" on the oxygen flow control valve were reset by the Ohmeda service engineer, which rectified the problem. It remains unclear why this problem occurred in new machines, within weeks of installation. We can only conclude that safety features incorporated in modern anesthetic machines are not infallible and clinical vigilance remains vital in preventing adverse outcomes while using them.

Manohar Lal Sharma MD FRCA

Liverpool, UK 


\section{References}

1 Ohmeda Excel 210 SE Anesthetic Machine Operation Manual.

2 Dorsh JA, Dorsh SE. The anesthesia machine. In: Retford DC (Ed.). Understanding Anesthesia Equipment, 3rd ed. Baltimore: William \& Wilkins, 1994: 51-90.

\section{The intubating laryngeal mask airway in severe ankylosing spondylitis}

To the Editor:

I would like to congratulate Dr. Lu et al. for their article "The intubating laryngeal mask airway in severe ankylosing spondylitis". ${ }^{1}$ The article contributes to the growing wealth of information regarding the applicability of the intubating laryngeal mask airway (ILM) in patients with difficult airways by direct laryngoscopy. There is, however, a small mistake in their discussion. They stated that "to our knowledge, this is the first report of ILM insertion following sevoflurane induction." Sevoflurane induction for insertion of ILM has been performed in many patients, both with and without difficult airways. ${ }^{2,3}$ The first report was back in March of 1998. This example goes to show that good ideas and sound planning are bound to be repeated.

Hwan Joo MD

Toronto, Ontario

\section{References}

1 Lu P-P, Brimacombe J, Ho ACH, Shyr M-H, Lin H-P. The intubating laryngeal mask airway in severe ankylosing spondylitis. Can J Anesth 2001; 48: 1015-9.

2 Joo H, Rose $K$. Fastrach-a new intubating laryngeal mask airway: successful use in patients with difficult airways. Can J Anaesth 1998; 45: 253-6.

3 Joo HS, Rose DK. The intubating laryngeal mask airway with and without fiberoptic guidance. Anesth Analg 1999; 88: 662-6.

\section{A normal capnogram despite esophageal intubation}

To the Editor:

The authors reported normal capnograms despite esophageal intubation in a spontaneously breathing patient, who had a difficult intubation. ${ }^{1}$ Given the sequence of events, experience suggests that a different scenario is more likely.
When the authors attempted a blind intubation, the tip of the tube could have been at or over the glottis, thereby producing normal $\mathrm{CO}_{2}$ waveforms as well as normal end-tidal $\mathrm{PCO}_{2}$ values during spontaneous ventilation. An armoured endotracheal tube can coil in the pharynx easily. On inflation of the endotracheal tube cuff, however, the tip of the tube dislodged out of the area above the glottis into the esophagus. This is consistent with the dramatic reduction in the endtidal $\mathrm{PCO}_{2}$ to values below $10 \mathrm{mmHg}$ from the initial values of $38-40 \mathrm{mmHg}$. Furthermore, passing even the smallest fibreoptic bronchoscope through a 6.0$\mathrm{mm}$ endotracheal tube requires considerable force which could have uncoiled the endotracheal tube, thereby, pushing the distal tip further along into the esophagus.

In absence of the following confirmatory tests, the hypothesis that the esophageal intubation produces normal $\mathrm{CO}_{2}$ waveforms may not be valid. The initial position of the endotracheal tube tip, before inflation of the cuff when $\mathrm{CO}_{2}$ waveforms were normal in shape and values, should have been confirmed via fibreoptic bronchoscope. Second, reproducing normal $\mathrm{CO}_{2}$ waveforms with normal end-tidal $\mathrm{PCO}_{2}$ values each time the cuff was deflated following inflation would strengthen the author's hypothesis that the endotracheal tube was indeed all along in the esophagus.

Kodali Bhavani Shankar MD

Matthew Posner MD FRCP

Boston, Massachusetts

\section{Reference}

1 Asai T, Shingu K. Case report: a normal capnogram despite esophageal intubation. Can J Anesth 2001; 48: $1025-8$.

\section{REPLY:}

I am aware of the possibility of an endotracheal tube being coiled in the pharynx (as cited such a report in my article), ${ }^{2}$ but would like to refute Drs. Shankar and Posner's claims.

They claim that passing even the smallest fibrescope through a $6.0 \mathrm{~mm}$ endotracheal tube requires considerable force. $I^{3,4}$ (as well as others) ${ }^{5}$ have used a fibrescope (diameter: 3.5 or $4.0 \mathrm{~mm}$ ) and a reinforced endotracheal tube (internal diameter: $6.0 \mathrm{~mm}$ ) in several studies and have never experienced such a difficulty.

They also suggest that insertion of a fibrescope could have uncoiled the endotracheal tube and pushed the tube tip further along into the esophagus. In the case presented, ${ }^{2}$ I could clearly see the distal aperture of the endotracheal tube even when the tip of the fibrescope was 5-6 cm proximal to the 